\title{
Educating For Tolerance And Compassion: Is There A Place For Meditation In A College Classroom? \\ Lana Zinger, Queensborough Community College
}

\begin{abstract}
Could contemplative practices change the way we think and act so that we move toward a more just, compassionate, and reflective classroom? The author's personal experiences and preparation for the practice, the content, the impact of the practice on students, and reflections on contemplative practice as a movement in education are offered as an example of the potential for contemplative education in a college classroom.
\end{abstract}

Keywords: Meditation in a classroom, Contemplative practices, Mindfulness education

\section{Introduction}

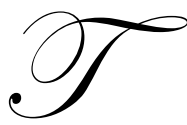

his article describes the development of experiential contemplative practices in mindfulness taught at a community college in NYC. The author's personal experiences and preparation for the practice, the content, the impact of the practice on students, and reflections on contemplative practice as a movement in education are offered as an example of the potential for contemplative education in a college classroom.

The current trend in our classrooms is to prepare students for standardized testing. Many students experience sitting in a stuffy classroom where the teacher continues to clutter their minds with facts that need to be memorized to compete for grades on exams. Students learn how to memorize, but rarely do they learn how to contemplate and create. We are well-practiced at educating the mind for critical reasoning, critical writing, and critical speaking, and for scientific and quantitative analysis. But many educators feel this is not sufficient. A change in methods is needed to help students repair their mental health through the introduction of spiritual development.

\section{Imagine A Classroom ...}

- Where there is minimal waste of time, confusion or disruption.

- Where a no-nonsense, work oriented tone prevails but there is a relaxed pleasant atmosphere.

- Where mutual respect is established.

- Where non-judgmental views are expressed when tackling controversial topics.

- Where we develop realistic ways of teaching and learning that moves us toward compassion and tolerance.

Contemplative practices are used to facilitate mindfulness in students, which can be characterized as the capacity to concentrate on the here and now. The goal is to have students become more attentive in the classroom or more focused on what they are reading or discussing. It is as if contemplative activity can cleanse the mind so that it can engage more fully with what one is currently experiencing even when living in a highly stressful environment. In the field of education, contemplative practices have been integrated into programs of teacher preparation so that they can become a source for innovative pedagogy, in which they help to shape not only how the teacher interacts with students but also how students interact with each other. 
Could contemplative practices change the way we think and act so that we move toward a more just, compassionate, and reflective classroom?

I began experimenting with contemplative practice as health professor at a community college in NYC. My health courses were centered on the issues of social justice, the environment, and peace education which demanded different educational skills. I felt that a teacher should not spend the whole class time on speaking, but to listen to the students, to ask questions that do not only recall factual information but to welcome students' insight, to encourage students' to express their views on such controversial issues without judgment. My goal was to teach the students to focus on issues in the classroom by tapping into their individual experiences of compassion and meaning. Compassion, of course, cannot be taught but it can be discovered or remembered. I've discovered that simple breath meditation can transform students' fundamental relation to themselves and their surrounding communities.

\section{Why I teach meditation in my classroom?}

Classroom Management through Meditation-I use meditation in the classroom when controversial issues arise. My goal was to teach students to be less reactive to life's annoyances and to respect one another's opinions.

Perception and Diversity- To help my students in understanding different points of view, expressing empathy and appreciating diversity.

Anger Management and Other Emotions-To teach my students how to cope with emotions such as sadness, fear and stress, and to sensitize students to their anger cues, triggers and style.

Effective Communication- To increase communication skills by teaching reflective listening, the use of I-statements and non-inflammatory ways of expressing one's needs and emotions.

\section{There are a number of other important reasons for bringing contemplative pedagogy into any classroom:}

- $\quad$ Reduced stress levels and lowered anxiety can have a noticeable effect on classroom productivity.

- $\quad$ Decreases in school absenteeism.

- Increased concentration and focus.

- Improved memory; and a greater ability to "be in the moment", to remove yourself from the chaos.

- $\quad$ Less stress when taking exams.

- $\quad$ Less panic attacks and anxiety especially during public speaking.

Meditation and mindfulness lets the students perceive the world, the classroom and other people more openly, with more compassion. Students who meditate have a more open awareness about socially defined categories such as one's sexuality, ethnicity, class and color. One begins to see them as they are, without putting them into categories.

\section{Meditation}

Meditation is simply directed concentration and involves focusing your awareness on an object: the breath, a repeated word or phrase (known as a mantra), or a mental image. By keeping your attention in one place, you're also removing your attention from anxious thoughts and the mental chatter that often fill our heads. In this way, meditation becomes a source of focus, energy, and awareness.

Mindfulness meditation is the practice of training the mind to focus in a steady and non-judging way on the different phases of human experience. With mindfulness meditation, we learn to experience non-judgmentally. A practice of seeing clearly, seeing things as they truly are, being aware of experiences. Recognizing the many pressures on undergraduates and their emotional needs, meditation in the classroom can be a powerful tool used to decrease stress and anger. For example, if a student gets very angry in the class while debating a controversial topic, meditation will teach how to observe the anger and form a non-judgmental solution, without answering in a quick, reactive manner. 
Educators emphasize speed in the classroom- hurry up and give me an answer is a common demand made by professors because time is of the essence. Meditation gives students time to reflect with their full powers of awareness. As educators, we need to resist the emphasis on speed because it leads to a decreased depth of comprehension and a superficial, distortion of thinking.

\section{Different contemplative techniques that I use in my classroom:}

Sustained attention using chime bells- When class lectures get too scientific and long and attention dwindles, I use chimes bells to bring focus back.

(1) Sound the bell three times. Listen intently to its form and timbre.

(2) Even after the bell sound has died away to outer silence, we possess the memory of the bell sound. We can resound the bell inwardly. Do so. Listen to its inner reverberation, again and again. (3) The third phase is that of silence. Allow the memory of the bell sound to fade, releasing all sound, and opening the attention wide.

Silence- I often begin my class with a moment of silence. It gives everyone a chance to settle in and to un-clutter our minds. I also use silence in the middle of the class, especially when a lot of information has been presented and students begin to get confused or frustrated. Silence gives students permission to be silent together to connect them to themselves and to each other in the class. . When students emerge form a moment of silence, they have a more profound sense of tolerance and understanding and are able to express their thought more coherently.

Classroom discussion- A significant amount of time is devoted to discussion during each class meeting. Discussion is centered on students' experiences with the various contemplative practices, insights drawn from viewing movies or reading articles, and sharing different perspectives using non-judgmental approaches. The purpose of such discussions is to help students articulate the nature of the mindfulness experiences in a reflective manner.

Journal writing- Journals are an important and intimate aspect of my courses. Every day I ask the students to keep a journal as a form of reflection and contemplation. The questions to reflect upon are:

What did I learn today about myself?

What moved me or inspired me today?

What could I have done differently today?

These questions help to reflect upon the day's experiences and to pay attention to the emotions. By reviewing the journals at various points during each semester, I gain a greater sense of the kinds of life circumstances, challenges, thoughts, and feelings many of these students are experiencing. Journal entries are so much deeper in thought, content and understanding than classroom discussion alone.

\section{Conclusions}

One size does not fit all. Students vary in learning styles and interests and it is also true with contemplative techniques. Different techniques may work better for different students. To bring mindfulness to the moment of teaching means bringing awareness to what students think and feel. It means that teachers learn to give up the desire for absolute control over this classroom space in order to create more tolerance, more openness, more listening and more room for exploration.

Contemplation is not a method, but rather a practice - an everyday practice that can transform our students' lives. Meditation in the classroom allows for greater self awareness. It enables students to notice their feelings and then create a space between their experience and their reactive response. Educators who care about nurturing awareness inside the classroom should consider adopting a contemplative practice.

Meditation is not a quick fix, but it can lead to compassion and a non-judgmental attitude resulting in a more productive classroom experience. 


\section{References}

1. $\quad$ Benson, H. (1975). The relaxation response. New York: HarperCollins.

2. Berryman, J. W. (1999). Silence is stranger than it used to be: Teaching silence and the future of mankind. Religious Education, 94, 257-272.

3. Dalai, L. (1995). World of Tibetan Buddhism: An overview of its philosophy and practice. Somerville, MA: Wisdom Books.

4. Davidson, R. J., Kabat-Zinn, J., Schumacher, J., Rosenkranz, M., Muller, D., Santorelli, S. F.,et al. (2003). Alterations in brain and immune function produced by mindfulness meditation. Psychosomatic Medicine, $65,564-570$.

5. $\quad$ Goldstein, J. (1994). Insight meditation: The practice of freedom. Boston: Shambhala Press.

6. Holland, D. (2004). Integrating mindfulness meditation and somatic awareness into a public educational setting. Journal of Humanistic Psychology, 44, 468-484.

7. Holland, D. (2005). Mindfulness meditation as a method of health promotion in educational settings: Proposal for an experiential pedagogy. Spektrum Freizeit:Forum fur Wissenschaft, Politik, and Praxis, 27(1), 107-115.

8. Kabat-Zinn, J., \& Chapman-Waldrop, A. (1988). Compliance with an outpatient stress reduction program: rates and predictors of program completion. Journal of Behavioral Medicine, 11, 333-352.

9. Kabat-Zinn, J., Lipworth, L., Burney, R., \& Sellers, W. (1987). Four-year follow-up of a meditation-based program for the self-regulation of chronic pain: Treatment outcomes and compliance. Clinical Journal of Pain, 2, 159-173

10. Kornfield, J. (1993). A path with heart: A guide through the perils and promises of spiritual life. New York: Bantam Books.

11. Rockefeller, S. (1996). Meditation, social change, and undergraduate education. Williamsburg, MA: The Center for Contemplative Mind in Society. 